\title{
Tobacco Advertising and Promotional Expenditures in Sports and Sporting Events — United States, 1992-2013
}

Israel T. Agaku, DMD ${ }^{1}$; Satomi Odani, $\mathrm{MPH}^{2}$; Stephanie Sturgis, $\mathrm{MPH}^{3}$; Charles Harless, $\mathrm{MPH}^{2}$; Rebecca Glover-Kudon, $\mathrm{PhD}^{1}$

Smokeless tobacco has been actively promoted by tobacco companies using endorsements by major sport figures, and research indicates that tobacco advertising can lead to youth initiation of tobacco use $(1,2)$. Television and radio advertisements for cigarettes and smokeless tobacco have been prohibited since 1969, ${ }^{*}$ and the 1998 Master Settlement Agreement ${ }^{\dagger}$ further prohibited tobacco companies from targeting youths with tobacco product advertisements in specified areas. In 2010, the Food and Drug Administration (FDA), under authority of the 2009 Family Smoking Prevention and Tobacco Control Act (FSPTCA), prohibited tobacco-brand sponsorship (i.e., sponsorship of sports and entertainment events or other social or cultural events using the tobacco brand name or anything identifiable with any brand of cigarettes or smokeless tobacco). ${ }^{\S}$ However, corporate-name tobacco sponsorship (i.e., sponsorship using the name of the corporation that manufactures regulated tobacco products) is still permitted under certain conditions. To monitor tobacco advertising and promotional activities in sports in the United States, CDC analyzed trends in sports-related marketing expenditures for cigarettes and smokeless tobacco during 1992-2013 using data from the Federal Trade Commission (FTC). During 1992-2013, sports-related marketing expenditures, adjusted by the consumer price index to constant 2013 dollars, decreased significantly for both cigarettes (from \$136 million in 1992 to $\$ 0$ in 2013) and smokeless tobacco (from $\$ 34.8$ million in 1992 to $\$ 2.1$ million in 2013). During 2010-2013, after the prohibition of tobacco-brand sponsorship in sports under the FSPTCA, cigarette manufacturers reported no spending (i.e., \$0) on sports-related advertising and promotional activities; in contrast, smokeless tobacco manufacturers reported expenditures of $\$ 16.3$ million on advertising and promoting smokeless tobacco in sports during 2010-2013. These findings indicate that despite prohibitions on brand sponsorship, smokeless tobacco products continue to be marketed in sports

\footnotetext{
*http://www.cdc.gov/tobacco/data_statistics/by_topic/policy/legislation/.

$\dagger$ In 1998, the Attorneys General of 46 states, the District of Columbia, and five U.S. territories signed the 1998 Master Settlement Agreement with the five largest U.S. tobacco companies, restricting youth-oriented tobacco advertising, marketing and promotion (https://oag.ca.gov/tobacco/resources/msasumm).

$\$$ RegulatoryInformation/ucm360573.htm.

Shttps://www.federalregister.gov/articles/2010/03/19/2010-6087/ regulations-restricting-the-sale-and-distribution-of-cigarettes-and-smokelesstobacco-to-protect.
}

in the United States, potentially through other indirect channels such as corporate-name sponsorship. Enhanced measures are warranted to restrict youth-oriented tobacco marketing and promotional activities that could lead to tobacco initiation and use among children and adolescents (2). Reducing tobacco industry promotion through sponsorship of public and private events is an evidence-based strategy for preventing youth initiation of tobacco use (3). In addition, other proven interventions (e.g., tobacco price increases, anti-tobacco mass media campaigns, tobacco-free policies inclusive of smokeless tobacco, and barrier-free access to cessation services), could help reduce smokeless tobacco use in the United States (1).

Marketing expenditures reported by tobacco companies during 1992-2013 were obtained from the FTC for cigarette and smokeless tobacco $(4,5)$. FTC classifies cigarette and smokeless tobacco** advertising and promotional expenditures into the following mutually exclusive categories: newspapers; magazines; outdoor; audio, visual; transit; point-of-sale; price discounts; promotional allowances (retailers, wholesalers, and other); sampling; specialty item distribution (branded and nonbranded); public entertainment (adult-only and generalaudience); sponsorships; endorsements and testimonials; direct mail; coupons and retail-value-added; Internet (including company website, social media, and other); telephone; and all other. Sports and sporting events expenditures are reported by tobacco companies as a component of one or more of these mutually exclusive categories. ${ }^{\dagger \dagger}$

Tobacco advertising in sports and sporting events was defined by FTC as expenditures used for 1) the sponsoring, advertising, or promotion of sports or sporting events; support of an individual, group, or sports team; and purchase of or support for equipment, uniforms, sports facilities, or training facilities; 2) advertising in the name of the tobacco company or any of its brands in a sports facility, on a scoreboard, or in conjunction with the reporting of sports results; and 3) functional

\footnotetext{
** Data collected from manufacturers of the following smokeless tobacco types: chewing tobacco, plug tobacco, scotch tobacco, moist snuff, snus, and dissolvable tobacco products.

†† The FTC requires tobacco manufacturers to report the total amount of money spent advertising at and promoting sports and sporting events. This question is separate from, and duplicative of, the reporting of the various distinct advertising and promotion categories. Thus, advertising expenditures for sports and sporting events could span across several of the distinct categories of tobacco advertising and promotion expenditures (e.g., general audience public entertainment, sponsorship, etc.)
} 
promotional items (e.g., clothing, hats, etc.) connected with a sporting event.

Data were analyzed separately for cigarettes and smokeless tobacco to assess total dollar expenditures, as well as the percentage of all marketing expenditures that were sports-related. Expenditures were adjusted for inflation using the consumer price index from the Bureau of Labor Statistics; the annual average consumer price index for 2013 was used as reference. Trends were assessed using Joinpoint regression $\$ \$(p<0.05)$; for sports-related cigarette marketing expenditures after 2005, joinpoints could not be assessed because these figures were not provided by FTC in 2006 and 2009 to avoid potential disclosure of individual company data. 99 In addition, annual percentage change (APC) and average annual percentage changes (AAPC) were computed to summarize the temporal trends during the study period.

Adjusted aggregate expenditures for smokeless tobacco marketing across all advertising and promotional categories was $\$ 191.5$ million in 1992 and $\$ 503.2$ million in 2013 (Table 1). Sports-related smokeless tobacco marketing expenditures decreased from $\$ 34.8$ million in $1992(18.2 \%)$ to $\$ 2.1$ million in $2013(0.4 \%)(\mathrm{p}<0.05)$. During 1992-2009, expenditures declined $(\mathrm{APC}=-5.4 ; 95 \%$ confidence interval $[\mathrm{CI}]=-7.6$ to -3.1) $(\mathrm{p}<0.05)$; steeper declines occurred during 2009-2013 $(\mathrm{APC}=-45.1 ; 95 \% \mathrm{CI}=-55.8$ to -31.8$)(\mathrm{p}<0.05)$. The overall rate of change (AAPC) during 1992-2013 was -14.7 (95\% $\mathrm{CI}=-18.3$ to -11.0$)$. The percentage of all marketing expenditures that were sports-related was higher for smokeless tobacco than cigarettes in each study year (Figure).

Adjusted aggregate expenditures for cigarette marketing across all advertising and promotional categories was $\$ 8.7$ billion in 1992 and $\$ 8.9$ billion in 2013 (Table 2). Sports-related cigarette marketing expenditures decreased from $\$ 136$ million in $1992(1.6 \%)$ to $\$ 0$ in 2013. Adjusted expenditures were stable during $1992-2001(\mathrm{APC}=4.1 ; 95 \% \mathrm{CI}=-0.9$ to 9.4$)$ and declined significantly during 2001-2005 (APC = -34.9; $95 \% \mathrm{CI}=-45.1$ to -22.8$)(\mathrm{p}<0.05)$. The overall rate of change (AAPC) during $1992-2005$ was $-9.9(95 \% \mathrm{CI}=-14.6$ to -4.9$)$.

\section{Discussion}

During 1992-2013, adjusted sports-related marketing expenditures decreased significantly for both cigarettes (from $\$ 136$ million in 1992 to $\$ 0$ during 2010-2013) and smokeless tobacco (from $\$ 34.8$ million in 1992 to $\$ 2.1$ million in 2013).

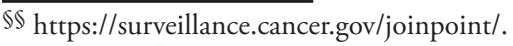

99 Estimates for sports-related cigarette marketing expenditures were reported by FTC as "N/A" in 2006 and 2009 because only one company reported spending money on a particular type of advertising or promotion. The expenditures for those years were included in the "All Others" category, to avoid potential disclosure of individual company data.
}

\section{Summary}

What is known about this topic?

Smokeless tobacco has been actively promoted in sports by tobacco companies using endorsements by major sport figures. In March 2010, the Food and Drug Administration, under authority of the 2009 Family Smoking Prevention and Tobacco Control Act, prohibited tobacco brand sponsorship of regulated tobacco products in sports and entertainment events or other social or cultural events.

What is added by this report?

During 1992-2013, sports-related marketing expenditures decreased significantly for both cigarettes (from $\$ 136$ million in 1992 to $\$ 0$ in 2013) and smokeless tobacco (from $\$ 34.8$ million in 1992 to $\$ 2.1$ million in 2013). After prohibition of tobacco brand sponsorship in sports in March 2010, cigarette manufacturers reported $\$ 0$ on sports-related advertising and promotion during 2010-2013. In contrast, during 2010-2013, smokeless tobacco manufacturers reported a total of $\$ 16.3$ million advertising and promoting smokeless tobacco in sports.

What are the implications for public health practice?

Restricting tobacco advertising and promotion in sports, coupled with other proven population-based measures (e.g., tobacco price increases, anti-tobacco mass media campaigns, tobacco-free policies inclusive of smokeless tobacco, and barrier-free cessation services), can help reduce tobacco use in the United States.

After prohibition of tobacco-brand sponsorship in sports in March 2010 under FSPTCA, sports-related marketing expenditures declined for smokeless tobacco during 2010-2013, although 2013 expenditures (\$2.1 million) represented an increase from 2012 expenditures (\$1.9 million). Notably, during 2010-2013, smokeless tobacco companies spent a total of $\$ 16.3$ million advertising and promoting smokeless tobacco in sports and sporting events. Moreover, although absolute sportsrelated marketing expenditures were higher for cigarettes than smokeless tobacco before 2009, the percentage of all marketing expenditures that were sports-related was higher for smokeless tobacco than cigarettes in each study year. Taken together, these findings suggest targeted marketing of smokeless tobacco products in sports and sporting events. Policies to reduce exposure of youths to sports-related advertising and promotion of smokeless tobacco might help reduce use of these products among youths (3). The dramatic decline in total cigarette and smokeless tobacco sports-related expenditures after the 1998 Master Settlement Agreement and subsequent prohibition of tobacco-brand sponsorship under FSPTCA correlates with the decrease in adult and teen smoking in the United States during the past two decades (1).

The World Health Organization recommends restrictions on direct and indirect forms of tobacco advertising, promotion, 
Morbidity and Mortality Weekly Report

TABLE 1. Total and sports-related smokeless tobacco* advertising and promotional expenditures, by year — United States, 1992-2013

\begin{tabular}{|c|c|c|c|c|c|}
\hline \multirow[b]{2}{*}{ Year } & \multicolumn{2}{|c|}{$\begin{array}{l}\text { Total expenditure on smokeless tobacco advertising/ } \\
\text { promotion, all categories }{ }^{\dagger} \text { (million \$) }\end{array}$} & \multicolumn{2}{|c|}{$\begin{array}{l}\text { Total expenditure on smokeless tobacco advertising/ } \\
\text { promotion, sports and sporting events }{ }^{\S} \text { (million } \$ \text { ) }\end{array}$} & \multirow{2}{*}{$\begin{array}{c}\text { Proportion of total advertising/ } \\
\text { promotion expenditures spent } \\
\text { on sports and sporting events } \\
\text { (\%) }\end{array}$} \\
\hline & Unadjusted & Adjusted? & Unadjusted & Adjusted ${ }^{\Upsilon}$ & \\
\hline 1992 & 115.3 & 191.5 & 21.0 & 34.8 & 18.2 \\
\hline 1993 & 119.2 & 192.2 & 22.7 & 36.7 & 19.1 \\
\hline 1994 & 126.0 & 198.0 & 24.5 & 38.5 & 19.5 \\
\hline 1995 & 127.3 & 194.6 & 25.9 & 39.5 & 20.3 \\
\hline 1996 & 123.9 & 183.9 & 19.8 & 29.4 & 16.0 \\
\hline 1997 & 150.4 & 218.3 & 25.8 & 37.4 & 17.1 \\
\hline 1998 & 145.5 & 207.9 & 26.6 & 38.0 & 18.3 \\
\hline 1999 & 170.2 & 238.0 & 23.4 & 32.7 & 13.8 \\
\hline 2000 & 224.6 & 303.8 & 11.0 & 14.9 & 4.9 \\
\hline 2001 & 236.7 & 311.3 & 17.9 & 23.5 & 7.6 \\
\hline 2002 & 234.6 & 303.8 & 21.1 & 27.3 & 9.0 \\
\hline 2003 & 242.5 & 307.0 & 16.9 & 21.4 & 7.0 \\
\hline 2004 & 231.1 & 285.0 & 20.6 & 25.5 & 8.9 \\
\hline 2005 & 250.8 & 299.1 & 15.7 & 18.8 & 6.3 \\
\hline 2006 & 354.1 & 409.2 & 16.9 & 19.5 & 4.8 \\
\hline 2007 & 411.2 & 462.0 & 17.9 & 20.1 & 4.4 \\
\hline 2008 & 547.9 & 592.8 & 14.6 & 15.8 & 2.7 \\
\hline 2009 & 492.1 & 534.4 & 15.2 & 16.5 & 3.1 \\
\hline 2010 & 444.2 & 474.6 & 9.0 & 9.6 & 2.0 \\
\hline 2011 & 451.7 & 467.8 & 3.4 & 3.6 & 0.8 \\
\hline 2012 & 435.7 & 442.1 & 1.8 & 1.9 & 0.4 \\
\hline 2013 & 503.2 & 503.2 & 2.1 & 2.1 & 0.4 \\
\hline
\end{tabular}

* Data collected from manufacturers of the following smokeless tobacco types on the U.S. market: chewing tobacco, plug tobacco, scotch tobacco, moist snuff, snus, and dissolvable tobacco products.

+ Includes aggregate expenditures across the different cigarette advertising and promotional categories: newspapers; magazines; outdoor; transit; point-of-sale; price discounts; promotional allowances (retailers, wholesalers, and other); sampling distribution; specialty item distribution (branded and nonbranded); public entertainment (adult-only and general-audience); sponsorships; endorsements and testimonials; direct mail; coupons; retail-value-added-nontobacco bonus; company website; internet-other; telephone; social media marketing; and other.

$\S$ Tobacco advertising in sports and sporting events was defined by the Federal Trade Commission (FTC) as 1) expenditures used for the sponsoring, advertising, or promotion of sports or sporting events; support of an individual, group, or sports team; and purchase of or support for equipment, uniforms, sports facilities, and/ or training facilities; 2 ) all expenditures for advertising in the name of the cigarette company or any of its brands in a sports facility, on a scoreboard, or in conjunction with the reporting of sports results; and 3) all expenditures for functional promotional items (clothing, hats, etc.) connected with a sporting event. Expenditures for sports and sporting events were not part of original line items collected by FTC for advertising and promotional expenditure categories, but were assessed by FTC from one or more of the above mutually exclusive categories (e.g., magazines, endorsements, sampling distribution, sponsorships, or outdoor).

" Dollar values were adjusted by the consumer price index (all items) to constant 2013 \$US.

and sponsorships. ${ }^{* * *}$ Tobacco-brand sponsorship prohibited under the FSPTCA distinguishes tobacco brand name from the corporate name. The rule prohibits the use of brand name (alone or in conjunction with any other word), logo, symbol, motto, selling message, recognizable color or pattern of colors, or other identifying features used for any brand of cigarettes or smokeless tobacco for sponsorship activities in sports and entertainment events or other social or cultural events. However, manufacturers, distributors, and retailers are permitted to conduct such sponsorships in their corporate name, if both the corporate name and the corporation were registered and in use in the United States before January 1, 1995, and the corporate name does not include any brand name or any of the other aforementioned brand characteristics (๑). Corporate-name

\footnotetext{
*** World Health Organization report on the global tobacco epidemic, 2013. Enforcing bans on tobacco advertising, promotion, and sponsorship (http:// apps.who.int/iris/bitstream/10665/85380/1/9789241505871_eng.pdf?ua=1).
}

tobacco sponsorship has the potential to maintain tobacco industry presence in sports, promote tobacco industry corporate image, and allow tobacco industry corporate names to be mentioned in media, even though cigarette and smokeless tobacco commercials are prohibited in broadcast media.

High prevalence of smokeless tobacco use has been reported among athletes at different levels, including among minor league baseball players (24.8\%), major league baseball players (36.0\%), and National Collegiate Athletic Association Division I male baseball players (49.6\%), and among male high school athletes (17.4\%) (7-9). To date, several U.S. cities, including Chicago, Illinois; San Francisco and Los Angeles, California; Boston, Massachusetts; and New York, New York, have passed legislation to prohibit smokeless tobacco use in public sports venues by players, coaches, referees, and fans. ${ }^{\dagger \dagger \dagger}$

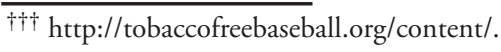


FIGURE. Sports-related cigarette and smokeless tobacco marketing expenditures and percentage of total expenditures* — United States, 1992-2013

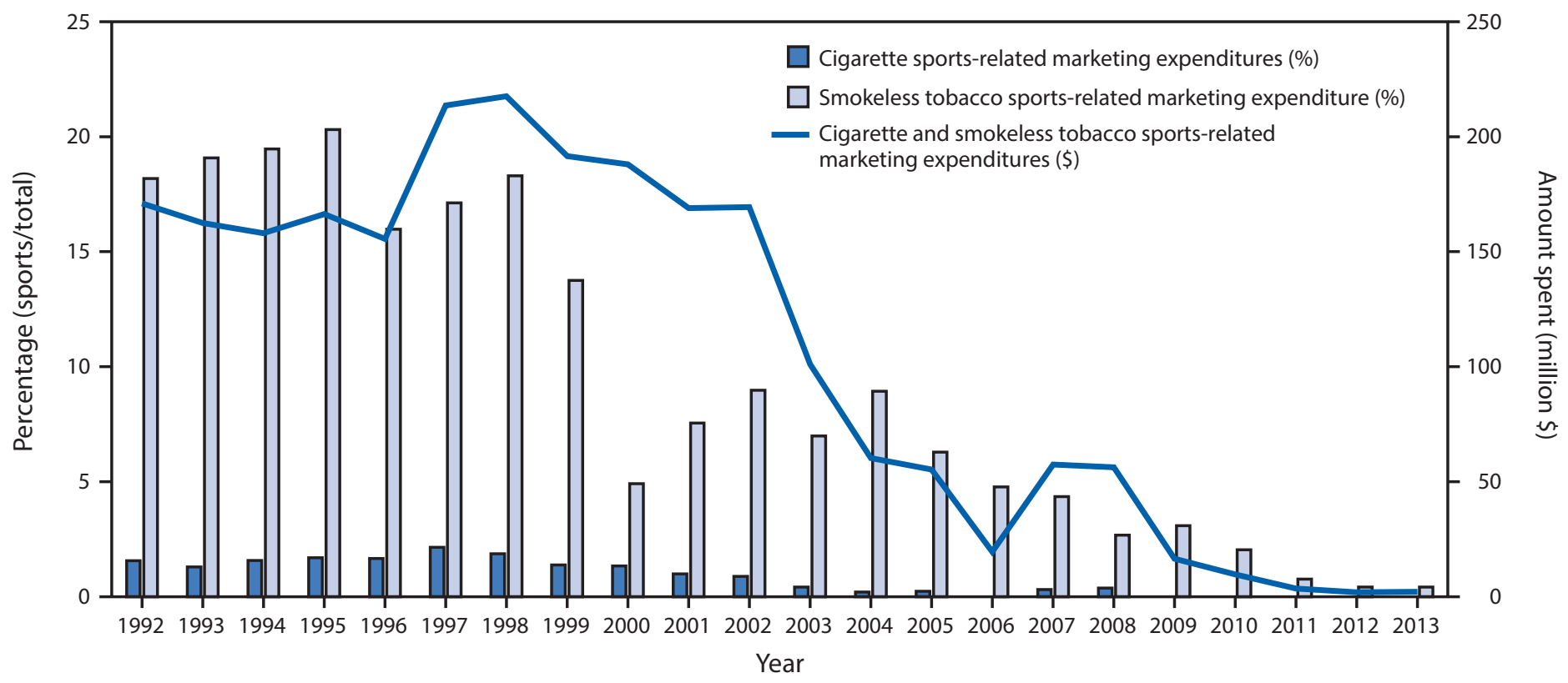

* Percentage of total cigarette and smokeless tobacco marketing expenditures that were spent in sports and sporting events.

Smokeless tobacco use among professional athletes has the potential to serve as an unpaid advertisement for these products, even in an environment where tobacco-brand sponsorship is prohibited. Professional athletes serve as role models for youths who might perceive such behavior as safe, socially acceptable, or a means to enhance athletic performance (8). However, smokeless tobacco use is not safe and can lead to nicotine addiction; oral, pancreatic, and esophageal cancer; and other oral conditions, including periodontal disease. $\$ \$ \$ \$$

The findings in this report are subject to at least two limitations. First, sports-related marketing expenditures were not disaggregated by the different advertising and promotional categories (e.g., Internet, specialty item distribution, magazines, etc.); therefore, determining what proportion of sports-related marketing expenditures was spent on specific advertising and promotional categories, especially those that appeal to youths, was not possible. Second, the amount of tobacco industry expenditures on advertising and promotion in sports might not necessarily correlate with actual levels of individual exposure to pro-tobacco marketing activities in sports.

Tobacco advertising and promotion might increase tobacco use by encouraging youths to experiment with and initiate regular tobacco use (10), deterring current tobacco users from quitting, prompting former tobacco users to relapse,

$\$ \$ \$ \$$ http://www.cancer.gov/about-cancer/causes-prevention/risk/tobacco/ smokeless-fact-sheet. and increasing intensity of tobacco use among current users by serving as external behavioral cues (2). Restricting tobacco advertising and promotion in sports, coupled with other proven population-based measures (e.g., tobacco price increases, antitobacco mass media campaigns, tobacco-free policies inclusive of smokeless tobacco, and barrier-free cessation services), can help reduce tobacco use in the United States (3).

\footnotetext{
${ }^{1}$ Office on Smoking and Health, National Center for Chronic Disease Prevention and Health Promotion, CDC; ${ }^{2}$ Rollins School of Public Health, Emory University, Atlanta, Georgia; ${ }^{3}$ McNeal Professional Services, Kennesaw, Georgia.

Corresponding author: Israel Agaku, IAgaku@cdc.gov, 770-488-5138.
}

\section{References}

1. US Department of Health and Human Services. The health consequences of smoking - 50 years of progress: a report of the Surgeon General. Atlanta, GA: US Department of Health and Human Services, CDC; 2014. http:// www.cdc.gov/tobacco/data_statistics/sgr/50th-anniversary/

2. US Department of Health and Human Services. Preventing tobacco use among youth and young adults: a report of the Surgeon General. Atlanta, GA: US Department of Health and Human Services, CDC; 2012. http:// www.surgeongeneral.gov/library/reports/preventing-youth-tobacco-use/

3. CDC. Preventing initiation of tobacco use: outcome indicators for comprehensive tobacco control programs-2014. Atlanta, GA: US Department of Health and Human Services, CDC; 2014. http://www. cdc.gov/tobacco/stateandcommunity/tobacco_control_programs/ surveillance_evaluation/preventing_initiation/index.htm

4. Federal Trade Commission. Federal Trade Commission cigarette report for 2013. Washington, DC: Federal Trade Commission; 2016. https:// www.ftc.gov/system/files/documents/reports/federal-trade-commissioncigarette-report-2013/2013cigaretterpt.pdf 
TABLE 2. Total and sports-related cigarette advertising and promotional expenditures, by year — United States, 1992-2013

\begin{tabular}{|c|c|c|c|c|c|}
\hline \multirow[b]{2}{*}{ Year } & \multicolumn{2}{|c|}{$\begin{array}{l}\text { Total expenditure on cigarette advertising } \\
\text { and promotion, all categories* } \\
\text { (billion \$) }\end{array}$} & \multicolumn{2}{|c|}{$\begin{array}{l}\text { Total expenditure on cigarette advertising and } \\
\text { promotion, sports and sporting events }{ }^{\dagger} \\
\text { (million \$) }\end{array}$} & \multirow{2}{*}{$\begin{array}{l}\text { Proportion of total advertising and } \\
\text { promotion expenditures spent on } \\
\text { sports and sporting events } \\
(\%)\end{array}$} \\
\hline & Unadjusted & Adjusted $^{\S}$ & Unadjusted & Adjusted $^{\S}$ & \\
\hline 1992 & 5.2 & 8.7 & 82.0 & 136.0 & 1.6 \\
\hline 1993 & 6.0 & 9.7 & 78.0 & 126.0 & 1.3 \\
\hline 1994 & 4.8 & 7.6 & 76.0 & 119.0 & 1.6 \\
\hline 1995 & 4.9 & 7.5 & 83.0 & 127.0 & 1.7 \\
\hline 1996 & 5.1 & 7.6 & 85.0 & 126.0 & 1.7 \\
\hline 1997 & 5.7 & 8.2 & 121.0 & 176.0 & 2.1 \\
\hline 1998 & 6.7 & 9.6 & 126.0 & 180.0 & 1.9 \\
\hline 1999 & 8.2 & 11.5 & 114.0 & 159.0 & 1.4 \\
\hline 2000 & 9.6 & 13.0 & 128.0 & 173.0 & 1.3 \\
\hline 2001 & 11.2 & 14.8 & 111.0 & 145.0 & 1.0 \\
\hline 2002 & 12.5 & 16.1 & 110.0 & 142.0 & 0.9 \\
\hline 2003 & 15.1 & 19.2 & 63.0 & 80.0 & 0.4 \\
\hline 2004 & 14.2 & 17.5 & 28.0 & 35.0 & 0.2 \\
\hline 2005 & 13.1 & 15.6 & 31.0 & 37.0 & 0.2 \\
\hline 2006 & 12.5 & 14.4 & N/Aq & N/A? & N/Aq \\
\hline 2007 & 10.9 & 12.2 & 33.0 & 37.0 & 0.3 \\
\hline 2008 & 9.9 & 10.8 & 37.0 & 40.0 & 0.3 \\
\hline 2009 & 8.5 & 9.3 & N/Aq & N/Aq & $\mathrm{N} / \mathrm{A}^{9}$ \\
\hline 2010 & 8.0 & 8.6 & 0.0 & 0.0 & 0.0 \\
\hline 2011 & 8.4 & 8.7 & 0.0 & 0.0 & 0.0 \\
\hline 2012 & 9.2 & 9.3 & 0.0 & 0.0 & 0.0 \\
\hline 2013 & 8.9 & 8.9 & 0.0 & 0.0 & 0.0 \\
\hline
\end{tabular}

* Includes aggregate expenditures across the different cigarette advertising and promotional categories: newspapers; magazines; outdoor; transit; point-of-sale; price discounts; promotional allowances (retailers, wholesalers, and other); sampling distribution; specialty item distribution (branded and nonbranded); public entertainment (adult-only and general-audience); sponsorships; endorsements and testimonials; direct mail; coupons; retail-value-added-nontobacco bonus; company website; internet-other; telephone; social media marketing; and other.

† Tobacco advertising in sports and sporting events was defined by the Federal Trade Commission (FTC) as 1) expenditures used for the sponsoring, advertising, or promotion of sports or sporting events; support of an individual, group, or sports team; and purchase of or support for equipment, uniforms, sports facilities, and/ or training facilities; 2 ) all expenditures for advertising in the name of the cigarette company or any of its brands in a sports facility, on a scoreboard, or in conjunction with the reporting of sports results; and 3) all expenditures for functional promotional items (clothing, hats, etc.) connected with a sporting event. Expenditures for sports and sporting events were not part of original line items collected by FTC for advertising and promotional expenditure categories, but were assessed by FTC from one or more of the above mutually exclusive categories (e.g., magazines, endorsements, sampling distribution, sponsorships, or outdoor).

$\S$ Dollar values were adjusted by the consumer price index (all items) to constant 2013 \$US.

" Estimates for sports-related cigarette marketing expenditures were reported by FTC as "N/A" in 2006 and 2009 because only one company reported spending money on a particular type of advertising or promotion. The expenditures for those years were included in the "All Others" category, to avoid potential disclosure of individual company data.

5. Federal Trade Commission. Federal Trade Commission smokeless Tobacco report for 2013. Washington, DC: Federal Trade Commission; 2016. https://www.ftc.gov/system/files/documents/reports/federal-tradecommission-smokeless-tobacco-report-2013/2013tobaccorpt.pdf

6. Cigarettes and smokeless tobacco. 21 C.F.R. Sect.1140.34 (2015). https://www.accessdata.fda.gov/scripts/cdrh/cfdocs/cfCFR/CFRSearch. cfm?fr $=1140.34$

7. Severson HH, Klein K, Lichtensein E, Kaufman N, Orleans CT. Smokeless tobacco use among professional baseball players: survey results, 1998 to 2003. Tob Control 2005;14:31-6. http://dx.doi.org/10.1136/ tc. 2004.007781
8. National Collegiate Athletic Association. 2013 study of substance use of college student-athletes. http://www.ncaa.org/sites/default/files/ Substance\%20Use\%20Final\%20Report_FINAL.pdf

9. Agaku IT, Singh T, Jones SE, et al. Combustible and smokeless tobacco use among high school athletes-United States, 2001-2013. MMWR Morb Mortal Wkly Rep 2015;64:935-9. http://dx.doi.org/10.15585/ mmwr.mm6434a2

10. Advertising of tobacco products. Hearings before the Subcommittee on Health and the Environment, Committee on Energy and Commerce, US House of Representatives, Ninety-ninth Congress, 2nd Session, July 18 and August 1, 1986. Serial no. 99-167. Washington, DC: US Government Printing Office, 1987:119-56. 